\title{
HAART Prescribing and BHIVA Standards of Care for People Living with HIV Audit
}

Dr Rob Howard, Mrs Dawn Killeen and Dr Zana Ladipo

\section{Background}

- We audited our service against the BHIVA 2013 Standards of Care for People Living with HIV, BHIVA treatment guidelines for HIV positive adults 2015 and North West 2015 treatment algorithm for HIV positive adults 2015 .

\section{Methods}

- This is a retrospective audit involving the review of all patient notes (84). 64 patients were excluded as they were started on medication before 2013.

\section{Results}

- First line therapy according to BHIVA 2015 guidance was prescribed in $100 \%$ of patients. Only 17\% (1/6) of patients had been prescribed treatment according to the North West 2015 HAART prescribing algorithm were prescribed first line therapies

- 55\% of patients were involved in their treatment decisions and $40 \%$ of patients were documented as being given advice regarding side effects.

- $100 \%$ of patients who had been started on ART adhered to their medication within the first 3 months.

- $75 \%$ of patients had had their viral load measured within the last 6 months and 10\% had moved out of the area. The remaining $15 \%$ had not had their viral loads done in 6 months as they had not attended their appointments. None of the patients who had viral loads done had experienced virological rebound.

- The GP was informed in only $35 \%$ of cases.

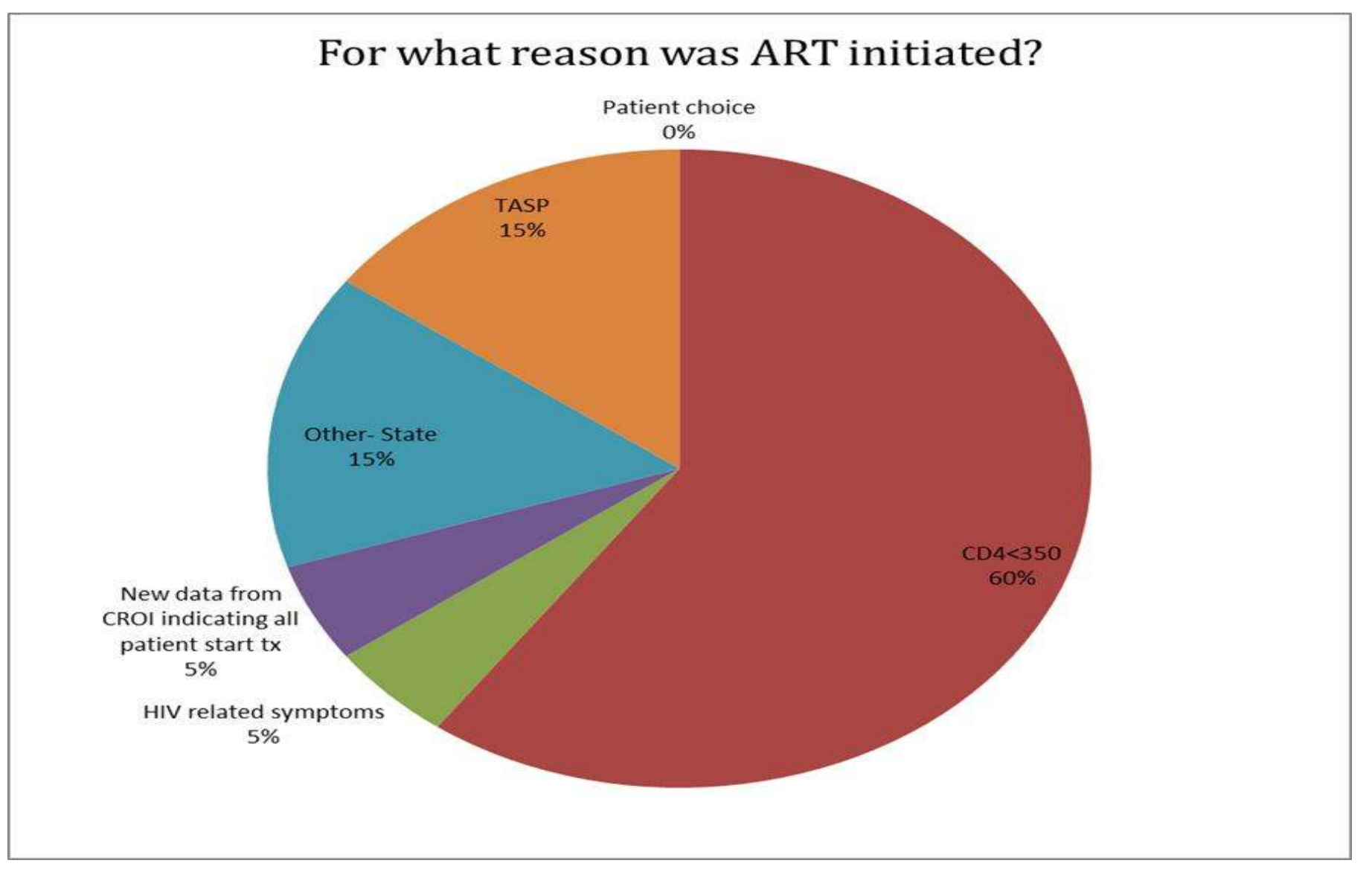

Of other: 1 was unclear

1 was due to pregnancy

1 was due to HIV encephalopathy

\section{Drug History}

Patients whose chemsex history was documented within the last 12 months

Patients whose recretional drug use was documented within the last 12 months

Patients who have had their ART meds reviewed within the last 12 months

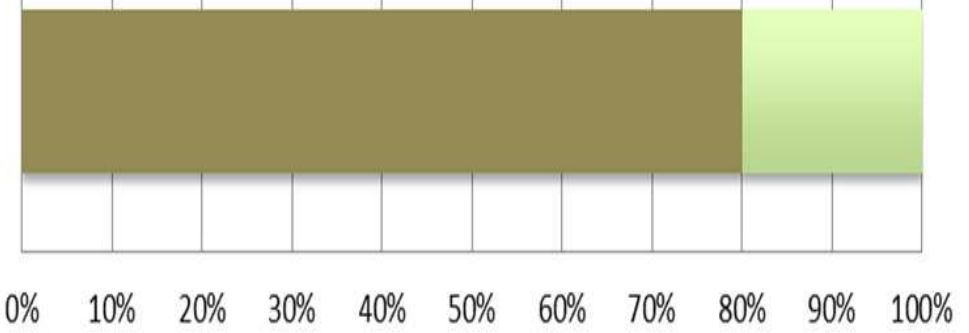

Patients who have had their ART meds reviewed Patients whose recretional drug use was Patients whose chemsex history was \begin{tabular}{c|c|c} 
& within the last 12 months & documented within the last 12 months \\
\hline yes & 16 & 2
\end{tabular} \begin{tabular}{l|l|l}
\hline no & 4
\end{tabular}

\section{Conclusions}

- We are $100 \%$ compliant to the BHIVA treatment guidelines while only $17 \%$ compliant to the North West algorithm.

- To improve our service and make it more viable, we will update our proforma according to the North West algorithm, which reflects the availability of cheaper generic drugs and NHS England guidance. 